\title{
DIAGNÓSTICO SOCIOECONÔMICO DE MARITURA (PA): REFLEXÕES E SUA INFLUENCIA NO DESENVOLVIMENTO DA AGRICULTURA URBANA E PERIURBANA
}

\author{
SILVA, Josiane Santos da ${ }^{1}$ \\ MARJOTTA-MAISTRO, Marta Cristina ${ }^{2}$
}

\begin{abstract}
RESUMO: O objetivo geral do artigo é construir um diagnóstico socioeconômico do município de Marituba, Estado do Pará, com intuito de embasar possíveis políticas públicas para a Agricultura Urbana e Periurbana (AUP). A metodologia utilizada foi o estudo de caso do município de Marituba, e as fontes consultadas para obtenção de dados secundários foram as bases de dados oficiais, como o Instituto Brasileiro de Geografia e Estatística (IBGE), dentre outros, além de artigos científicos consultados através das bases de dados Portal de Periódico Capes/MEC e Scielo. Os resultados indicam o precário desenvolvimento do município em relação a Belém, com respeito à infraestrutura, principalmente, de segurança e saneamento básico. Por outro lado, referente à educação e saúde, o município apresenta características de relativo desenvolvimento, já que possui um IDHM considerado médio em relação aos outros municípios brasileiros, e neste caso, as dimensões educação e saúde tiveram forte influência na melhoria do IDHM. A agricultura em Marituba funciona em sistema diversificado, e é essencialmente produtora de hortaliças e pode ser caracterizada como familiar e urbana e periurbana, pois é conduzida em áreas próximas ao centro urbano. De maneira geral, o município apresenta características socioeconômicas com potencial para o desenvolvimento da AUP, e essa conjuntura pode ser mais uma contribuição no processo de ampliação das melhorias no município e por isso necessita de estímulos e incrementos às Políticas Públicas e ações voltadas para seu fortalecimento e consolidação.
\end{abstract}

Palavras-Chave: Diagnóstico. Indicadores socioeconômicos. Políticas públicas. AUP.

SUMMARY: The general objective of the article is to construct a socioeconomic diagnosis of the municipality of Marituba, State of Pará, in order to support possible public policies for Urban and Peri-urban Agriculture (AUP). The methodology used was the case study of the municipality of Marituba, and the sources consulted for obtaining secondary data were the official databases, such as the Brazilian Institute of Geography and Statistics (IBGE), among others, besides scientific articles consulted through of the Capes / MEC and Scielo Journal Portal databases. The results indicate the precarious development of the municipality in relation to Belém, with respect to the infrastructure, mainly, of security and basic sanitation. On the other hand, referring to education and health, the municipality presents characteristics of relative development, since it has an average HDI in relation to other Brazilian municipalities, and in this case, the education and health dimensions had a strong influence on the improvement of the HDI. Agriculture in Marituba operates in a diversified system, and is essentially producer of vegetables and can be characterized as familiar and urban and periurban because it is conducted in areas near the urban center. In general, the municipality presents socioeconomic characteristics with potential for the development of UPA, and this conjuncture can be another contribution in the process of expansion of the improvements in the municipality and for this reason it needs stimuli and increments to the Public Policies and actions aimed at its strengthening and consolidation.

Keywords: Diagnosis. Socioeconomic indicators. Public politics. AUP.

\section{INTRODUÇÃO}

O crescimento urbano modificou a distribuição da população brasileira, e nos últimos 50 anos houve aumento na população urbana em detrimento da rural, de $25 \%$ para aproximadamente $84 \%$ do total, segundo dados do IBGE de 2010. Esse aumento chocou-se com a falta de infraestrutura na educação,

\footnotetext{
${ }^{1}$ Universidade Federal de São Carlos- UFSCar

${ }^{2}$ Universidade Federal de São Carlos (UFSCar), Depart. de Tecnologia Agroindustriall e Socioeconomia Rural
} 
saúde, moradia, saneamento básico, segurança alimentar e geração de emprego e renda (SANTANA, 2016). Contrariamente ao que se imaginava, a cidade e seus sistemas econômicos não conseguiram suprir as necessidades socioculturais e de qualidade de vida da população, além de não absorver esta mão de obra que praticamente só conhece o trabalho agrícola (BELTRAN, 1995). O que contradiz a máxima de que o êxodo rural levaria a "liberdade" que existe na cidade, longe do atraso encontrado no meio rural (SANTANA, 2016).

O modo de viver e alimentar-se na cidade é diferente do campo, uma vez que as famílias, antes rurais, se apropriam desse novo modo de vida, e muitas vezes perdem seus saberes e transformam seus costumes alimentares (BELTRAN, 1995). Essas mudanças causaram distanciamento entre homem e natureza, porém, em algumas regiões do mundo, com particularidade, nos países em desenvolvimento, algumas iniciativas vieram na contramão dos processos de urbanização, como manutenção ou criação de atividades agrícolas em áreas urbanas ou periurbanas. Essas formas, além de combater as situações precárias em que vive grande parte dos citadinos urbanos, também mostra que a ligação entre homem e terra não foi totalmente perdida e que é possível produzir em espaços não rurais mostrando a importância da agricultura urbana e periurbana (UNDP, 1996).

A Agricultura Urbana e Periurbana no município de Marituba já viveu um fértil período de produção agrícola, principalmente hortaliças folhosas. E segundo Santos e Silva (2007), 87\% dos produtores, de três dos maiores bairros do município, tinham essa atividade como principal fonte de renda. Tendo esse contexto em mente, este trabalho busca conhecer a atual conjuntura política e social desse modo de produzir implantado em Zonas Urbanas e/ou Periurbanas.

Assim, o objetivo geral do artigo é construir um diagnóstico socioeconômico do município de Marituba, Estado do Pará, com intuito de embasar possíveis políticas públicas para o desenvolvimento da Agricultura Urbana e/ou Periurbana (AUP). O objetivo específico procura apresentar características socioeconômicas do município por meio de indicadores tais como: Indicadores de Desenvolvimento Municipal como o Produto Interno Bruto do município (PIB), Índice de Desenvolvimento Humano (IDHM) e Índice de Gini, Demografia, Segurança Pública, Educação, Alimentação Escolar, Agricultura, Saúde e Saneamento Básico. Esses indicadores foram escolhidos por serem os mais utilizados para a implementação e avaliação de programas sociais do governo federal. Baseado no diagnóstico, busca-se refletir sobre seus resultados e possíveis contribuições para as políticas públicas que venham a desenvolver as AUP na região.

O artigo está estruturado em cinco tópicos. No primeiro consta a introdução. No segundo são apresentados os procedimentos metodológicos nos quais o trabalho foi realizado. O terceiro corresponde a discussão teórica sobre Agricultura Urbana e Periurbana (AUP) e Políticas Públicas, bem como se tem uma discussão sobre a importância do diagnóstico e dos indicadores na construção e avaliação de políticas públicas, o quarto retrata os resultados e discussão que é propriamente o diagnóstico do município, e no quinto tópico as considerações finais.

\section{PROCEDIMENTOS METODOLÓGICOS}

O estudo foi realizado no município de Marituba, Estado do Pará, Região Norte do país que está localizado na Região Metropolitana de Belém, distante $13 \mathrm{~km}$ da capital do Estado, Belém, pela Rodovia Federal BR 316. Faz limite ao Norte e a leste com o Município de Benevides e Santa Bárbara do Pará, ao Sul com os Municípios de Acará e Belém, e ao Oeste com Ananindeua (IBGE, 2010), está situado a 24 metros de altitude do nível do mar e está localizado nas coordenadas geográficas: Latitude: $1^{\circ} 21^{\prime} 19^{\prime \prime}$ Sul, Longitude: $48^{\circ} 20^{\prime} 36^{\prime \prime}$ Oeste (figura 1). 
Figura 1: Região Metropolitana de Belém, com destaque para o município de Marituba.

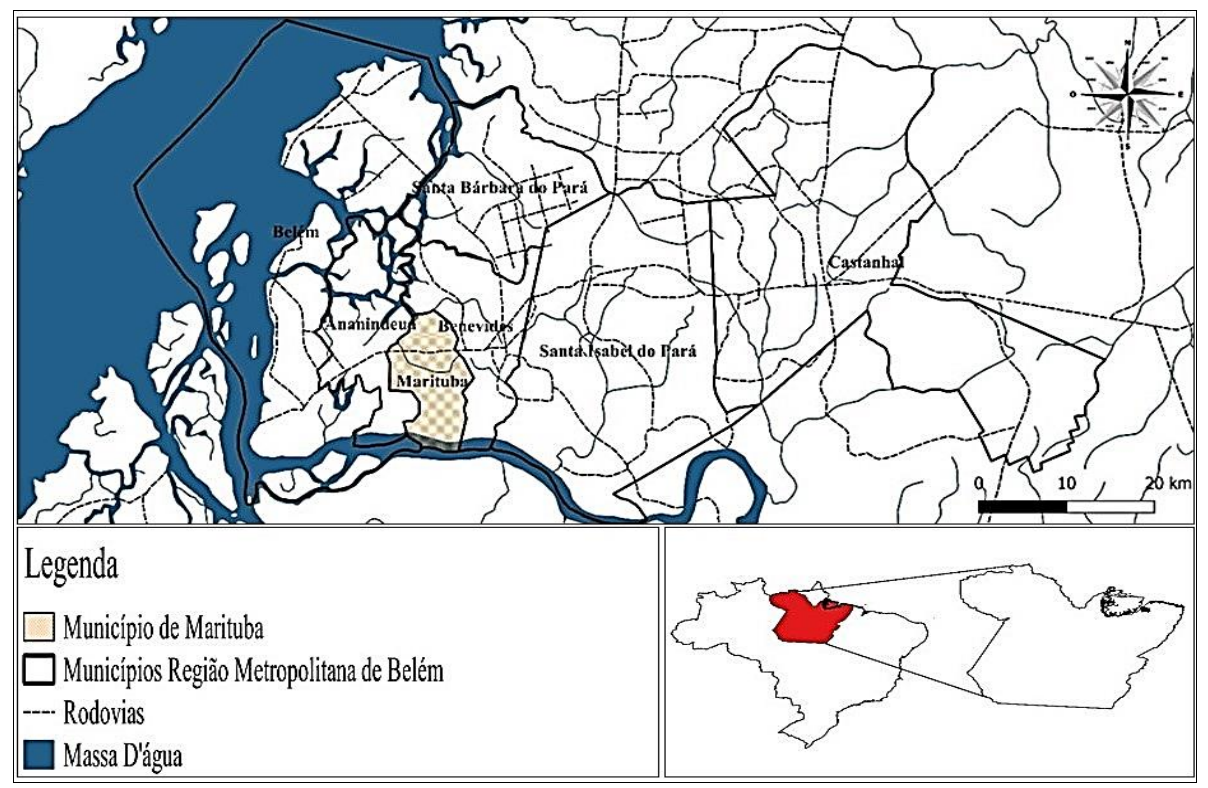

Fonte: Silva, 2018.

A investigação foi de natureza exploratória e a metodologia utilizada para a análise é o estudo de caso do município de Marituba. As fontes consultadas para obtenção de dados secundários foram as bases de dados oficiais de instituições públicas e privadas, como o Instituto Brasileiro de Geografia e Estatística (IBGE), Ministério da Educação, DATASUS do Ministério da Saúde, Instituto de Pesquisa Econômica Aplicada (Ipea), Fundação Amazônia de Amparo a Estudos e Pesquisas (FAPESPA) dentre outros, além de artigos científicos consultados através das bases de dados Portal de Periódico Capes/MEC e Scielo.

\section{REVISÃO TEÓRICA}

\subsection{Agricultura Urbana e Periurbana (Aup) e Políticas Públicas}

Existem várias definições para a agricultura urbana (AU) e agricultura periurbana (AP) variando conforme o enfoque. Para a organização internacional Research Urban Agriculture Foundation (RUAF), agricultura urbana é o cultivo de plantas e a criação de animais dentro e ao redor da cidade e Mougeot (2000) enfatiza sua produção em pequenas extensões de terra e locais, como tetos e hortas em terrenos e espaços públicos ociosos.

Segundo o atual Ministério do Desenvolvimento Social e Agrário (MDSA) e a Food and Agriculture Organization (FAO, 2011), suas multifuncionalidades podem incentivar a criação de políticas e ações voltadas para melhorar a gestão ambiental e territorial, promover a igualdade de gêneros e respeito às condições étnicas e socioculturais, combater a pobreza, a insegurança alimentar, nutricional e a fome; além de promover a inclusão social e participativa.

Apesar de bastante conhecida e praticada em todo o mundo, a Agricultura Urbana e Periurbana, no Brasil, ainda é relativamente nova em termos de divulgação de pesquisas. A discussão sobre esse conceito nasceu inicialmente a partir do Programa das Nações Unidas para Assentamentos Humanos (UNHABITAT) na década de 1980 e se deu através de debates a respeito das estruturas das cidades, vindo para o Brasil posteriormente na década de 1990 com interesse principalmente da agenda de Segurança Alimentar e Nutricional - SAN (CNAU, 2015). Esse posicionamento da SAN foi um catalisador para 
inclusão das hortas comunitárias no Programa Fome Zero, do governo federal, o que gerou bases para construção dos conceitos e objetivos da Agricultura Urbana (AU) no Brasil (CNAU, 2015).

Após 2004 e 2007, nas II e III Conferência Nacional de Segurança Alimentar e Nutricional (CNSAN) a agricultura urbana foi recomendada como opção para o abastecimento e forma de melhor utilização dos espaços ociosos nas cidades. No relatório final da III CNSAN, pôde-se observar um maior direcionamento em termos práticos para políticas públicas para AUP, nele foram trilhadas estratégias que abrangiam: criação da Política Nacional de Agricultura Urbana e Periurbana, segurança alimentar, dotação orçamentária e linha de crédito especial para os agricultores urbanos, inclusive índios não aldeados em linhas de créditos, com ênfase na produção de base agroecológica e de economia solidária.

Outros passos foram dados em direção ao fortalecimento de políticas para AUP, como a criação da Coordenação Geral de AUP, através do atual Ministério do Desenvolvimento Social e Agrário (MDSA). E também o lançamento da Portaria $n^{\circ} 467$ de fevereiro de 2018, que institui o Programa Nacional de Agricultura Urbana e Periurbana publicado através do Diário Oficial da União, pelo MDSA. Esta portaria dentre outras coisas, institui no Art. $2^{\circ}$, um conjunto de iniciativas que visam potencializar as ações de segurança alimentar, promover a educação ambiental e estimular hábitos saudáveis (BRASIL, 2018, p.1).

A portaria ainda propõe metas para AUP onde pretende no: Art. $3^{\circ} \mathrm{I}$ - formalizar parcerias na perspectiva de promover a agricultura urbana, na forma de produção agrícola sustentável, comunitária e/ou doméstica, por meio da introdução de tecnologias de produção sustentáveis como catalizador da segurança alimentar, geração de renda e inclusão social; II - fomentar o desenvolvimento de ações voltadas para a gestão e o aperfeiçoamento das ações de agricultura urbana e periurbana; III - promover a conscientização de possíveis financiadores para a agricultura urbana e periurbana; e IV - sensibilizar as esferas estaduais e municipais para desenvolver políticas regionais e municipais de agricultura urbana e periurbana, principalmente nas escolas e associações comunitárias.

No artigo $4^{\circ}$, a portaria afirma que a execução do Programa Nacional de Agricultura Urbana e Periurbana poderá ser realizada através de "contratos, acordos de cooperação, termos de execução descentralizada, ajustes ou outros instrumentos congêneres com órgãos e entidades da administração pública federal, dos Estados, do Distrito Federal e dos Municípios, inclusive consórcios públicos, e com entidades privadas, na forma da legislação pertinente" (BRASIL, 2018, p. 2).

A criação desse cenário de políticas e incentivos sinaliza um avanço no tema discutido, essa portaria de 2018 concretiza, pelo menos no papel, as iniciativas, parcerias e prováveis formas de execução do Programa Nacional de Agricultura Urbana e Periurbana no Brasil.

Na Região Metropolitana de Belém, Estado do Pará, existiu o Centro de Apoio à Agricultura Urbana e Periurbana (CAAUP) criado em 2008, com duração de dois anos, sendo prorrogado até maio de 2010. Este era um instrumento da política de segurança alimentar e nutricional do governo federal, onde articulava pesquisa, ensino e extensão junto a Incubadora Tecnológica de Cooperativas Populares e Empreendimentos Solidários (ITCPES), vinculada ao Instituto de Ciências e Tecnologia (ITEC) e Instituto de Ciências Aplicadas (ICSA), da Universidade Federal do Pará (UFPA). O público alvo foi formado por assentamentos (Elizabeth Teixeira, Paulo Fonteles), a Comunidade 19 de Abril e o Movimento de Mulheres das Ilhas de Belém (MMIB), moradoras da Ilha de Cotijuba.

O CAAUP buscava a associação entre o conhecimento acadêmico-científico e o conhecimento popular, desenvolvendo ações de assistência técnica e fomento criando condições para enfrentamento da fome e da miséria na região (NEVES et al., 2010). Porém, segundo o relatório final da CAAUP Belém (2010), houve vários pontos a serem considerados sobre o Centro e suas atividades. O principal foi a falta de continuidade do projeto apesar de terem alcançado maior parte das metas programadas, também houve atraso no repasse das verbas e problemas com as licitações. O que dificultou a execução de todas as 
atividades previstas. Outro ponto importante foi à falta de mobilização dos agricultores de Marituba que não participaram do projeto.

Como fatores positivos, podem ser apontados a gestão de empreendimentos sob a ótica do trabalho coletivo, como vertente da sustentabilidade e associado à economia solidária e à agroecologia (NEVES et al., 2010). Atualmente, esse projeto não existe mais e por enquanto não há indicação de seu retorno.

Todas as ações discutidas anteriormente são importantes para o debate a respeito da $\mathrm{AU}$, pois se vê um relativo esforço em busca de construir um cenário onde a AUP tenha visibilidade e possa desenvolver sua já mencionada multiplicidade e ampliar seus aspectos sociais, políticos, econômicos e culturais inerentes a cada localidade. Para que esse cenário efetivamente se realize é necessário a intervenção de políticas públicas, e que estas gerem impactos sobre a população, e estejam em consonância aos diagnósticos e planejamentos, embasados nos interesses da comunidade. Assim o presente artigo irá construir um diagnóstico que será apresentado em tópicos nos resultados.

\subsection{A Importância do Diagnóstico e dos Indicadores na Construção e Avaliação de Políticas Públicas}

O diagnóstico é um instrumento utilizado para compreender uma realidade social, e registrar os principais problemas do local de estudo (MEREGE, 2011). Faz uma representação inicial de uma realidade que será a base para auxiliar a deliberação de questões prioritárias a serem atendidas, a elaboração de estratégias, programas e ações na esfera das políticas públicas (JANNUZZI, 2005)

Importante salientar que o diagnóstico é somente uma parte do processo de construção das políticas públicas, pois de nada adianta diagnosticar problemas e não contar com um planejamento para solucioná-los. O diagnóstico restringe-se a expor problemas e suas causas, o planejamento tem início com o diagnóstico e é finalizado com a programação das ações e dos procedimentos de avaliação (TÔSTO, 2003). Essa análise socioeconômica deve ser construída com base em indicadores confiáveis, válidos e desagregados que possam abarcar várias dimensões da realidade social (LIMA; ANDRADE; BARCELOS, 2013) e assim possam ser utilizados para elaboração de políticas ou programas sociais.

Para Jannuzzi (2005), no âmbito das políticas públicas, os "indicadores sociais mostram, indicam, aproximam traduzem em termos operacionais as dimensões sociais de interesse, definidas a partir de escolhas teóricas ou políticas realizadas anteriormente" (p.138, 2005). Muitos estudos vêm utilizando a técnica do diagnóstico com diferentes enfoques, como as questões socioambientais (TACHIZAWA, 2009; DAL MORO, 2015), e as socioeconômicas (LIMA; ANDRADE; BARCELOS, 2013; TÔSTO et al., 2003; MEREGE, 2011; DA NÓBREGA JÚNIOR, 2015).

Lima, Andrade e Barcelos (2013), apresentaram um diagnóstico socioeconômico de Minas Gerais nas reuniões dos Comitês de Gestão Regionalizada e Participativa, onde se buscou auxiliar na construção coletiva da imagem da região. Esses dados forneceram elementos de diferentes áreas com objetivo de esclarecer ao gestor regional uma perspectiva territorial, temporal e multissetorial da região em que operam (LIMA; ANDRADE; BARCELOS, 2013). No mesmo trabalho, observou-se que a apresentação do diagnóstico para os gestores os fez avaliar a região de maneira mais holística, para além das perspectivas de suas áreas, e descobrir quais desafios encarados pela região e quais estratégias devem ser aplicadas para solucionar os problemas apontados.

O trabalho de Da Nóbrega Júnior (2015), buscou revelar dados e informações pontuais a respeito da desigualdade e pobreza em uma microrregião da Paraíba, o Cariri Ocidental paraibano, avaliando se houve evolução nos aspectos socioeconômicos e qual nível de desigualdade ainda permeia a região. Os resultados indicaram um alto nível de desigualdade e pobreza na Paraíba. Apesar da presença das 
Universidades federal e estadual, pouco se observou em relação a mudanças em termos de redução da desigualdade. $\mathrm{O}$ artigo propõe um desenvolvimento construído através de bases sustentáveis, e para isso a necessidade de conhecer os aspectos socioeconômicos dessa microrregião a fim de promover melhor adaptação de políticas públicas sociais que mudem a realidade da população do Cariri Ocidental e assim reduzir as desigualdades ainda vigentes, além da melhoria dos indicadores em longo período.

Sabe-se da importância dos indicadores para a composição do diagnóstico, porém, muitas vezes existem dificuldades em acompanhar os programas, devido falta de informações periódicas e específicas sobre o procedimento de implantação e da abrangência dos resultados e impacto social da política, seja através dos indicadores ou nas comunidades em que foram objeto de aplicação (JANNUZZI, 2005).

Os indicadores podem ser classificados em: indicadores analíticos e sintéticos. A diferença entre eles, o próprio nome indica, um tem por objetivo traduzir formas mais analíticas, e o outro, formas mais sintéticas de demonstrar a conjuntura a que se propõem. O IDH-M, por exemplo, é um indicador sintético, pois, corresponde a uma média das vertentes, educação, alfabetização, renda média e esperança de vida. Em outras palavras, faz uma síntese de várias dimensões da realidade social e/ou econômica em uma única medida. Enquanto, a taxa de evasão escolar, por exemplo, é a representação do indicador analítico, já que demonstra medida relacionada à questão social ligada especificamente ao campo da educação.

Apesar das críticas feitas em relação aos indicadores sintéticos, muitos deles já adquiriram legitimidade social, política, técnica e científica, pois, vários projetos obtiveram financiamento de agências nacionais e internacionais de pesquisa, devido seus dados e principalmente, pensando no proposito deste trabalho, possuem forte apelo como ferramenta na construção de políticas públicas (JANNUZZI, 2005).

Para esta pesquisa foram encontradas as mesmas dificuldades de dados atualizados e específicos, por exemplo, sobre a agricultura praticada em áreas urbanas. E por esse fato, buscou-se trabalhar outros indicadores e artigos que validasse ou não a propensão do município de Marituba a Agricultura Urbana e Periurbana. E assim discutir a necessidade de políticas públicas e, que estas, sejam de interesse para o município e auxilie no fortalecimento da AUP.

\section{RESULTADO E DISCUSSÃO}

\subsection{Alguns Aspectos Socioeconômicos de Marituba, PA}

Nesse tópico serão considerados alguns aspectos socioeconômicos de Marituba, dentre eles: Indicadores de Desenvolvimento Municipal (PIB, IDH e Índice de Gini), Demografia, Segurança Pública, Educação, Alimentação Escolar, Agricultura, Saúde e Saneamento Básico.

\section{Indicadores de Desenvolvimento Municipal}

Os indicadores de desenvolvimento escolhidos foram o PIB municipal, o IDH municipal e o Índice de Gini municipal.

Conforme dados do Censo Demográfico (IBGE, 2015), a população ocupada no município de Marituba era de 14,4\% (17.735), e o percentual da população com rendimento nominal de até meio salário mínimo era de 42,4\%. A média mensal de salário para os trabalhadores formais era de 2,2 salários mínimos, enquanto a capital Belém oferecia 3,7 de média salarial. 
Em dez anos, a taxa de atividade ou percentual de pessoas economicamente ativas (18 anos ou mais) passou de 60,69\%, em 2000, para 63,74\%, em 2010. Em contrapartida, as taxas de pessoas desocupadas caíram de 21,55\% em 2000, para 14,34\% em 2010 (PNUD, Ipea).

Na tabela 1, tem-se o Produto Interno Bruto (PIB) do município de Marituba no ano de 2013, por setor econômico. Nele é possível observar a maior participação dos serviços (49\%), seguida por administração e serviços públicos (26\%), impostos (14\%), indústria (12\%) e a pouco expressiva agropecuária.

Tabela 1: Produto Interno Bruto (PIB) de Marituba no ano de 2013.

\begin{tabular}{ccc}
\hline Atividade & Valor líquido (R\$) & Taxa (\%) \\
\hline Agropecuária & $4.334,95$ & $\sim 0,0$ \\
Indústria $^{1}$ & $133.129,35$ & 12,0 \\
Serviços $^{1}$ & $558.796,35$ & 49,0 \\
Administração e Serviços Públicos & $298.438,43$ & 26,0 \\
Impostos & $157.326,90$ & 14,0 \\
Total & $1.152 .025,99$ & 100,0 \\
\hline
\end{tabular}

Fonte: IBGE em parceria com os Órgãos Estaduais de Estatística, Secretárias Estaduais de Governo e Superintendência da Zona Franca de Manaus - SUFRAMA, 2013. ${ }^{1}$ Exclusive Administração e Serviços Públicos.

O gráfico 1 mostra a evolução do Produto Interno Bruno (PIB) per capita de Belém, e Marituba entre os anos de 2010 a 2014. Conforme os dados do gráfico houve uma evolução no PIB per capita em Belém de R\$13.50 (2010) para R\$20.03 (2014), em Marituba se observou um aumento de R\$ 5.05, no mesmo período. A complementar, dados do IBGE (2015), indicaram mais uma evolução no PIB de Marituba de R\$ 11,81 (2011) para R\$ 13. 02, em 2015. Um crescimento também foi observado em Ananindeua (R\$2,86) e Benevides (R\$ 7,08) conforme se vê no gráfico abaixo (FAPESPA, 2017).

Gráfico 1: Evolução do Produto Interno Bruto per capita anual dos municípios paraenses - 2010 a 2014 $(\mathrm{R} \$)$

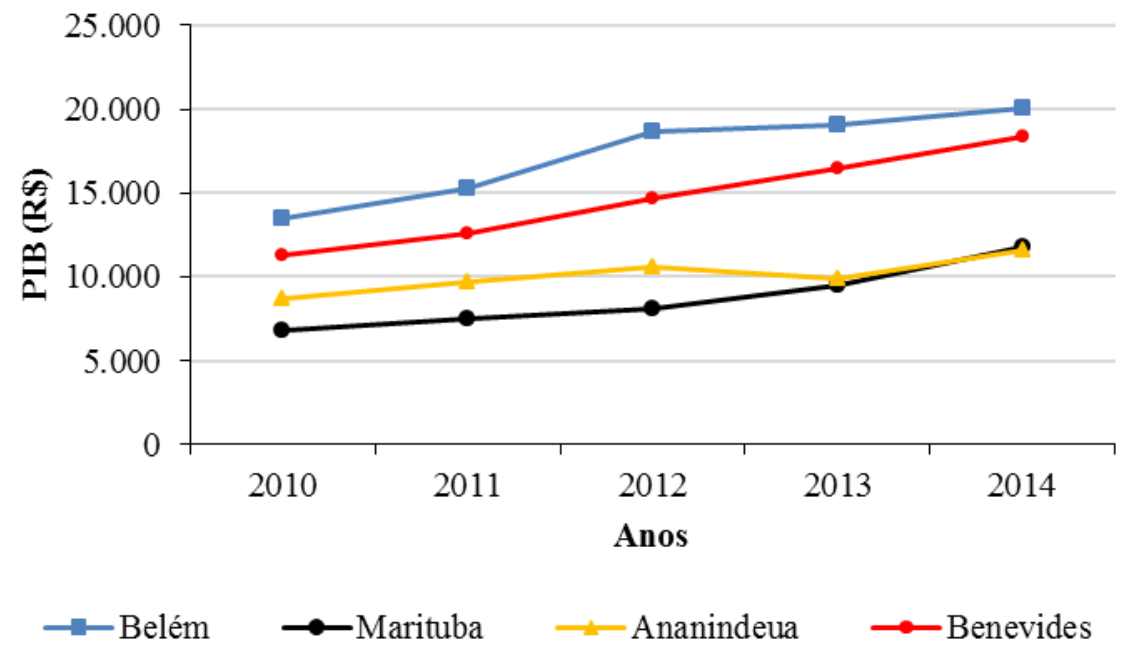

Fonte: FAPESPA, 2017.

O Programa das Nações Unidas para o Desenvolvimento (PNUD) instituiu o indicador nomeado Índice de Desenvolvimento Humano (IDH) que busca pôr em paralelo os índices do PIB per capita, já que 
este avalia somente os aspectos econômicos do desenvolvimento. Em outras palavras o IDH é uma versão mais abrangente e envolve as dimensões PIB per capita, educação e longevidade (PNUD, 2010).Na pesquisa foi utilizado o Índice de Desenvolvimento Humano Municipal (IDHM) que é uma versão regional do IDH, mas que abarca as dimensões educação, longevidade e renda. Em Marituba, durante uma década (2000 a 2010) o IDHM evoluiu a uma taxa de 33,86\% e no período indicado a dimensão que mais desenvolveu foi a educação, com aumento de $0,28 \%$.

O IDHM de Marituba era de 0,676 (2010), este índice é considerado médio, segundo o Programa das Nações Unidas para o Desenvolvimento (PNUD), pois, se encontra entre 0,600 e 0,699 (tabela 2) colocando o município no quinto lugar no ranking estadual, sendo o limite máximo 1 e o mínimo 0.

$\mathrm{Na} \mathrm{RMB}$, os municípios, de forma geral se categorizaram na faixa do índice de IDHM médio $(0,600$ até 0,699$)$, com exceção dos municípios de Belém e Ananindeua que indicaram IDHM alto na faixa de 0,700 até 0,799 , conforme tabela 2 .

Tabela 2: Ranking IDHM por dimensão, da Região Metropolitana de Belém, Estado do Pará, 2010.

\begin{tabular}{cccccc}
\hline $\begin{array}{c}\text { Ranking no } \\
\text { Estado }\end{array}$ & Município & IDHM & $\begin{array}{c}\text { IDHM } \\
\text { Renda }\end{array}$ & $\begin{array}{c}\text { IDHM } \\
\text { Longevidade }\end{array}$ & $\begin{array}{c}\text { IDHM } \\
\text { Educação }\end{array}$ \\
\hline $1^{\circ}$ & Belém & 0.746 & 0.751 & 0.822 & 0.673 \\
$2^{\circ}$ & Ananindeua & 0,718 & 0,684 & 0,821 & 0,658 \\
$5^{\circ}$ & Marituba & 0.676 & 0.621 & 0.793 & 0.628 \\
& & & & \\
$6^{\circ}$ & Castanhal & 0,673 & 0,654 & 0,800 & 0,528 \\
$12^{\circ}$ & Benevides & 0,665 & 0,623 & 0,798 & 0,592 \\
$15^{\circ}$ & Santa Isabel do & 0,659 & 0,622 & 0,798 & 0,576 \\
& Pará & & & & 0,546 \\
$29^{\circ}$ & Santa Bárbara do & 0,627 & 0,575 & 0,784 & 0,546 \\
& Pará & & & & \\
\hline
\end{tabular}

Fonte: Atlas do Desenvolvimento Humano, 2010.

Em Marituba, assim como de maneira geral no Brasil, observou-se uma evolução no desenvolvimento humano, apesar de a renda per capita ter diminuído, segundo dados da Pesquisa Nacional de Amostra por Domicílios (PNAD) de 2015 (PNUD; FJP; Ipea).

Em dez anos, o índice de Gini ${ }^{3}$ de Marituba sofreu queda de 0,52 para 0,42, entre os anos de 2000 e 2010, respectivamente, conforme tabela 3 . Essa tendência pode indicar melhoria na distribuição de renda entre os munícipes.

Tabela 3: Índice de Gini da renda domiciliar per capita segundo município no período de 1991, 2000 e 2010.

\begin{tabular}{cc}
\hline dice de Gini da renda domiciliar per capita de Marituba (1991, 2000 e 2010) \\
\hline 1991 & 0,53 \\
2000 & 0,52 \\
2010 & 0,42 \\
\hline
\end{tabular}

Fonte: DATASUS e IBGE/Censos Demográficos 1991, 2000 e 2010.

\footnotetext{
${ }^{3}$ O índice de Gini foi criado pelo estatístico italiano Conrado Gini, em 1912, com finalidade de medir o grau de desigualdade social, concentração de renda, concentração de terra e riqueza em determinado grupo, seja município, estado ou país. Em outras palavras ele mostra o índice de desigualdade ou a diferença entre a renda dos mais ricos e dos mais pobres. Por regra varia de 0 a 1 . Onde 0 representa igualdade, aqui todos estão em situação de mesma renda, o 1 indica desigualdade ou acúmulo de renda nas mãos de poucos (IPECE, 2010).
} 
Os dados discutidos nesta sessão podem indicar ocorrência de melhorias nas condições básicas de vida da população local. Essas melhorias são retratadas por indicadores como o PIB per capita, IDHM e Índice de Gini. A queda no coeficiente de desigualdade (Gini) é termômetro que mostra a distribuição de renda em determinado local. Conforme trabalho realizado por Lylla (2016), há correlação negativa entre esse índice e a taxa de vítimas de acidente de trânsito e suicídio, por exemplo, retratando que a diminuição da taxa de pessoas pobres e extremamente pobres esta significativamente correlacionadas com o aumento do número de mortes violentas no período estudado fato fortemente influenciador na taxa de longevidade, componente do IDHM que naturalmente indicou mudança de correlação positiva para negativa em relação as mesmas referências.

A evolução positiva demonstrada através dos indicadores pode indicar o resultado da implantação de alguns programas do governo federal, como o Programa Bolsa Família (PBF) que busca contribuir para o combate à pobreza e à desigualdade no Brasil, através de avanços no acesso à educação, à saúde e à assistência social (BRASIL, 2003). Segundo Néri et al., (2014) as políticas sociais, como o Bolsa Família contribuíram fortemente na melhoria de vida das pessoas e Da Nóbrega Junior (2015), associa também, além das políticas de redistribuição de renda, a estabilidade monetária do país, que o elevou ao patamar de "muito baixo desenvolvimento humano no início da década de noventa, para um nível de alto desenvolvimento humano já em 2008" (p.91, 2015). Inclusive fazendo com que o Brasil fosse premiado pelas Nações Unidas por alcançar sua meta do milênio antes de o prazo acordado.

Em Marituba o ingresso de famílias no PBF aumentou de 11.751 para 11.928 famílias (gráfico 2). Esses números são relativos em relação aos municípios da RMB, pois, em Belém esse acréscimo foi de 27.122 famílias (84.202 em 2011 e 111.324, em 2015), enquanto em Santa Bárbara, 0,301 famílias (2.031 em 2011 e 2.332 , em 2015).

Gráfico 2: Famílias atendias pelo Programa Bolsa Família nos municípios do Pará, no período de 2011 a 2015.

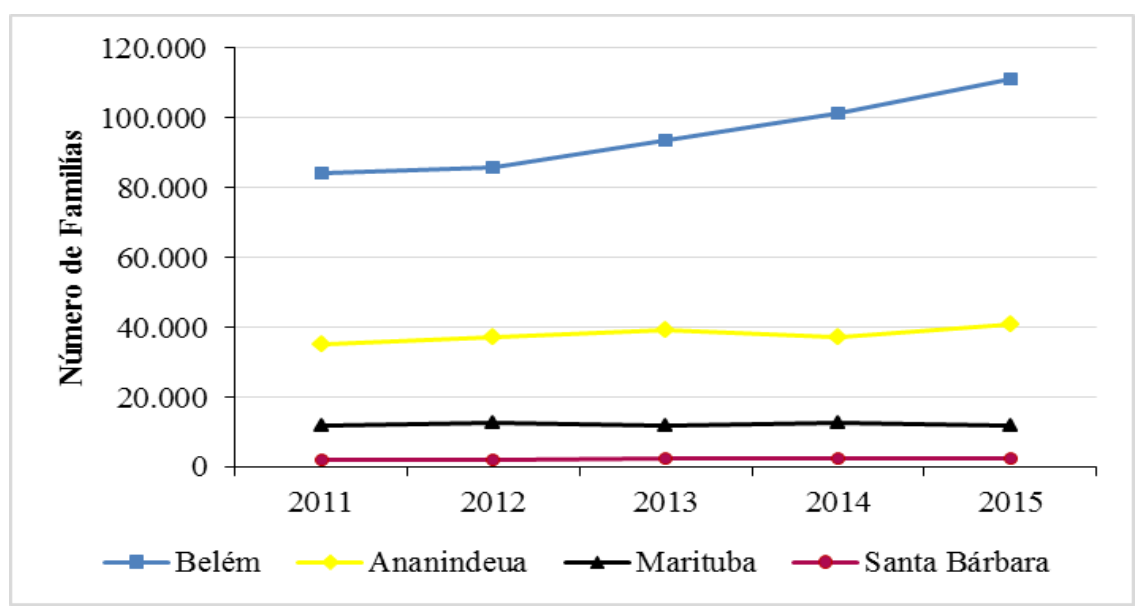

Fonte: FAPESPA

Trabalho realizado por Kuhn (2017), no Rio Grande do Sul mostrou que, de maneira geral, as condicionantes do PBF ampliam as oportunidades dos contemplados à saúde e educação, além de observar relações positivas entre o acesso ao programa e outros elementos importantes do desenvolvimento. Subsídios esses que ultrapassam os recursos econômicos, como melhoria nas condições materiais e importantes contribuições relativas ao conhecimento.

\section{Demografia}

Segundo o IBGE (2010), Marituba possuía uma densidade demográfica de 1.047,44 ha/km², e população urbana de 107.123 habitantes, enquanto a rural 1.123 (tabela 4), sua população estimada, em 
2018, era de aproximadamente 129.321 habitantes e sua área territorial 103,343 km². Em 2015, era o nono maior município do Pará (Marituba/PA).

O município de Marituba obteve uma taxa média anual de crescimento populacional em torno de $3,82 \%$, entre os anos de 2000 e 2010, enquanto o Brasil apresentou uma taxa de 1,17\% no mesmo período. Ainda nesta época, Marituba, demonstrou uma evolução na taxa de urbanização de 87,18\%, para 98,96\% (IBGE, Censo demográfico, 2000 e 2010).

A taxa da população por gênero pouco diferiu entre os anos de 2000 e 2010, de 49,47\% (36.823) para $49,78 \%$ (53.884), respectivamente, entre os homens. As mulheres demonstraram um aumento de 37.606 para 54.362 na década indicada. A população urbana teve acréscimo de 87,18\% (64.884) para $98,96 \%$ (107.123), por outro lado, a rural apresentou decréscimo de 12,82\% para 1,04\% (tabela 4). Esse rápido decréscimo ocorrido na população rural pode ser justificado, conforme Lima, Cardoso e Holanda (2005), devido a migrações para os centros urbanos, como Belém, ou devido às "transformações parciais de áreas rurais em conjuntos habitacionais e ocupações informais que foram reconhecidos como bairros". Outro ponto importante é o Plano Diretor de Marituba que não descrimina Área de Expansão Urbana e Zona Rural ficando esta última compreendida na citada área de expansão urbana (MARITUBA, 2007, p. 83), criando dificuldades tanto aos órgãos de recenseamento quanto aos agricultores e moradores que lá vivem.

Tabela 4: População residente Total, por gênero, Rural/Urbana - Município de Marituba - PA.

\begin{tabular}{ccc}
\hline & Ano- 2000 & Ano- 2010 \\
\hline População Total & 74.429 & 108.246 \\
\hline Homens & 36.823 & 53.884 \\
\hline Mulheres & 37.606 & 54.362 \\
\hline Urbana & 64.884 & 107.123 \\
\hline Rural & 9.545 & 1.123 \\
\hline
\end{tabular}

Fonte: IBGE, Censo demográfico, 2000 e 2010.

Na tabela 4, observa-se nos grupos por idade que o município abriga uma população de 42.218 habitantes entre 20 e 39 anos e 41.385 na faixa de 0 a 19 anos. Percebe-se uma queda na população do meio rural conforme aumenta a idade, a exceção está no grupo de 20 a 39 anos que demonstrou acréscimo. Na zona urbana aparentemente ocorre a mesma situação da zona rural, houve decréscimo na população conforme aumentou a idade, exceto para faixa de 29 a 39 anos que apresentou ampliação.

Ainda na tabela 4, a taxa de envelhecimento calculada pela razão entre a população de 65 anos ou mais em relação à população total aumentou de 2,94\% para 3,45\% (PNUD, Ipea, IBGE, CENSO DOMOGRÁFICO, 2000 e 2010). Segundo Malta (2008), a marcante queda de fecundidade associado à redução da mortalidade, resultou em um processo de envelhecimento populacional, consideravelmente maior que em outras populações mais desenvolvidas, no século passado. Essas mudanças afetam diretamente o Sistema Único de Saúde (SUS), já que irá demandar aumento nos serviços de saúde especializados e maior necessidade de políticas públicas e programas que atendam a esse público (CAMPOS, 2017). Ainda segundo a autora, nos municípios paraenses, assim como na população brasileira, a taxa de envelhecimento aumentou corroborando os dados desta pesquisa, e influenciando a razão de dependência que é a taxa percentual da população com menos de 15 anos e da população de 65 anos e mais. Essa taxa caiu de 62,91\% para 47,52\% em 10 anos, entre os anos de 2000 a 2010, respectivamente (tabela 5). A queda na taxa da razão de dependência em Marituba tende a indicar a capacidade da população em idade produtiva em sustentar o contingente 
populacional potencialmente inativo do município.

Tabela 5. População residente por grupo de idade em Marituba - PA (2010).

\begin{tabular}{|c|c|c|}
\hline \multicolumn{3}{|c|}{ Estrutura etária da População em Marituba - PA - 2010.} \\
\hline \multicolumn{3}{|l|}{ Grupo de idade (anos) } \\
\hline & \multicolumn{2}{|c|}{ População (2010) } \\
\hline \multirow{4}{*}{$0-19$} & Total & 41.385 \\
\hline & Rural & 385 \\
\hline & Urbana & 41.000 \\
\hline & Total & 42.218 \\
\hline \multirow[t]{3}{*}{$20-39$} & Rural & 437 \\
\hline & Urbana & 41.781 \\
\hline & Total & 18.887 \\
\hline \multirow[t]{3}{*}{$40-59$} & Rural & 263 \\
\hline & Urbana & 18.624 \\
\hline & Total & 5.756 \\
\hline \multirow[t]{2}{*}{60 a 70 anos ou mais } & Rural & 37 \\
\hline & Urbana & 5.719 \\
\hline Razão de dependência & & 62,91 \\
\hline Taxa de envelhecimento & & 3,45 \\
\hline
\end{tabular}

Fonte: PNUD, Ipea, Censo demográfico, 2010.

\section{Segurança Pública}

A segurança em Marituba retratada pelo Sistema de Indicadores Sociais (SIIS, 2010) indica um município violento com taxa de ocorrência de roubos por 100.000 habitantes de 114, 46\%, já a taxa de homicídio em mesma proporção foi de 12,29\% quase duas vezes maior que Belém, a capital do Estado, a qual indicou $6,06 \%$ (tabela 6). A alta taxa de latrocínio $(0,92 \%)$ e estupro $(7,91 \%)$ também evidenciam a insegurança vivida pela população local.

Tabela 6: Ocorrência de crimes, um comparativo entre Belém e Marituba, 2010.

\begin{tabular}{ccc}
\hline Ocorrência (por 100.000 habitantes) & Belém & Marituba \\
\hline Roubos & 188,09 & 114,46 \\
Homicidio & 6,06 & 12,29 \\
\hline Tentativa de Homicidio & 2,00 & 1,76 \\
\hline Latrocinio & 0,54 & 0,92 \\
\hline Estupro & 6,96 & 7,91 \\
\hline Total das Ocorrências Registradas Polícia Civil & 200,36 & 133,40
\end{tabular}

Fonte: SIIS, 2010. 
Os dados apontam elevadas taxas de criminalidade o que mostra situação semelhante a encontrada por Ramão (2008), no Paraná, onde verificou alta taxa de crimes violentos, e que para a autora, estão associados a deficiências na infraestrutura urbana somada as desigualdades sociais e econômicas. E, nesse contexto, em que ocorra "sobreposição de carências", e logo baixa qualidade de vida da população residente, torna-se fácil a formação de cenários típicos para aquelas ocorrências. Ainda segundo Ramão (2008), há de se considerar a taxa de urbanização na dinâmica dos homicídios no cenário nacional. Em Marituba, segundo o Censo de 2010, essa taxa chegou a 98,96\%, enquanto o Brasil foi de $84,36 \%$ e a região Norte $73,53 \%$. Os dados mostraram o município de estudo com alta taxa de urbanização ao nível nacional, o que pode indicar relação com aumento da violência. A rápida urbanização e expansão demográfica não acompanhou a distribuição de recursos básicos garantidores de vida digna a grande parte da população, excluindo algumas regiões e priorizando outras. Essa fragmentação do espaço reflete a distância nas relações sociais, o que pode fomentar a violência local (SOUZA, 2004).

\section{Educação}

No município de Marituba, em 2015 existiam 766 docentes lecionando no ensino fundamental (EF), 223 no ensino médio (EM) e 142 no ensino pré-escolar (EPE). Estes dados podem demonstrar que o número de docentes por categoria de ensino (ensino médio, ensino fundamental e ensino pré-escolar) estava acompanhando o percentual de matrículas escolares no ano indicado.

No EF a taxa de matrícula foi de 68\% (17.184), no EM de 21\% (5.380), e no ensino pré-escolar um percentual de $11 \%$ (2.715). A respeito dos estabelecimentos de ensino, os dados indicavam também um acompanhamento de acordo com os números de docentes e matrículas por faixa de ensino, sendo 64 de ensino fundamental, 10 escolas de ensino médio e 44 de ensino pré-escolar (INEP, Censo Educacional, 2015).

Os alunos do $4^{\mathrm{a}}$ ao $5^{\mathrm{a}}$ ano da rede pública tiveram nota média de 4.3 no Índice de Desenvolvimento da Educação Básica (Ideb) de 2015, enquanto os alunos do $8^{\mathrm{a}}$ ao $9^{\mathrm{a}}$ ano obtiveram índice de 3.7. O alcance das metas projetadas para o Ideb em cada faixa de ensino mostrou-se aquém da apresentada efetivamente (tabela 7). Além disso, a escala do índice varia de zero a 10 o que mostra pouca evolução nas notas do Ideb municipal.

O Ideb é composto por indicadores importantes da educação, como o fluxo escolar e as médias de desempenho nas avaliações do Instituto Nacional de Estudos e Pesquisas Educacionais Anísio Teixeira (Inep) e esses dados são fortemente utilizados para indicar a conjuntura do sistema educacional e é importante embasador para políticas públicas (BRASIL, Inep).

Tabela 7: Notas das escolas de rede de ensino Público, federal, estadual e municipal no município de Marituba, 2007 - 2015.

Ideb - Rede de ensino: Pública, federal, estadual e municipal

\begin{tabular}{ccccccc}
\hline & 2007 & 2009 & 2011 & 2013 & 2015 & 2017 \\
Ideb observado (4 ${ }^{\mathrm{a}}$ a $5^{\mathrm{a}}$ série) & 3.3 & 4.0 & 4.0 & 3.8 & 4.3 & - \\
Metas projetadas & 3.2 & 3.5 & 3.9 & 4.2 & 4.5 & 4.8 \\
Ideb observado $\left(8^{\mathrm{a}}\right.$ a $9^{\mathrm{a}}$ ano) & 3.5 & 3.8 & 3.8 & 3.4 & 3.7 & - \\
Metas projetadas & 3.4 & 3.5 & 3.8 & 4.2 & 4.6 & 4.8 \\
\hline
\end{tabular}

Fonte: INEP.

Outro dado importante é a taxa de escolarização líquida do município que, em 2010, foi de 95.5 para estudantes de 6 a 14 anos, enquanto a capital Belém obteve 96.1, essa taxa se refere a percentagem de 
alunos de um grupo etário, em relação ao grupo total de pessoas na mesma situação (IBGE, Censo demográfico, 2010).

A dimensão educação do IDHM é composta por escolaridade da população adulta e o fluxo escolar dos jovens. Os dados indicam que em 19 anos (1991 a 2010) as taxas tiveram aumento de 54,21\% (5 a 6 anos), 51,33\% (11 a 13 anos), 46,39\% (15 a 17 anos) e 27,28\% (18 a 20 anos) (PNUD, 2010).

A expectativa de anos de estudo no município é calculada medindo a frequência escolar da população em idade escolar (PNUD, 2013). Ela indica a quantidade de anos que um aluno leva desde o início de sua vida escolar padrão, até completar 18 anos. O Atlas Brasil utiliza a expectativa de 12 anos como o máximo de estudo da educação formal, ensino básico. Em Marituba, essa expectativa passou de 7,42 anos para 9,20, em 10 anos.

Na tabela 8, pode-se visualizar a taxa de evasão escolar do ensino médio e fundamental no município de Marituba. Essa taxa mede o percentual de alunos evadidos, ou seja, os alunos que não seguem matriculados na série seguinte a que estão (INEP). No ensino fundamental percebe-se uma taxa praticamente constante no tempo analisado, enquanto no ensino médio houve oscilações durante todo o período, em cinco anos a queda foi de $28 \%$ (2011) para 22,9\% (2015).

Tabela 8: Taxa de evasão escolar em Marituba (\%).

\begin{tabular}{cccccc}
\hline Faixas de Ensino & & Anos & \\
& 2011 & 2012 & 2013 & 2014 & 2015 \\
Ensino fundamental (6 aos 15 anos) & 3,2 & 3,6 & 3,4 & 3,2 & 3,2 \\
Ensino Médio (14 aos 18 anos) & 28,0 & 25,9 & 28,2 & 25,7 & 22,9 \\
\hline
\end{tabular}

Fonte: Fonte: FAPESPA e INEP, 2017.

Em 2000, os estudantes de 18 a 24 anos, cursando o ensino superior, era de 1,02\%, em 2010, essa taxa aumentou para 5,64\% o que demonstra aumento da presença de jovens nas faculdades. Essa ampliação pode indicar maior participação nos programas governamentais de incentivo, como o Programa Universidade Para Todos ${ }^{4}$ (Prouni). Estas vagas podem ocorrer em cursos de graduação e sequenciais de formação específica para estudantes brasileiros sem diploma de nível superior (BRASIL, Prouni).

\section{Alimentação escolar - Programa Nacional de Alimentação Escolar (PNAE)}

A discussão sobre educação alimentar teve sua origem nos anos de 1930 e 1940 devido manifestações de movimentos sociais por merenda escolar. E em 1955 foi assinado o Decreto n. ${ }^{\circ} 37.106$ originando a Campanha da Merenda Escolar (CME) que posteriormente teve seu nome modificado e somente em 1979 recebeu o nome Programa Nacional de Alimentação Escolar (PNAE), comumente conhecido como "merenda escolar" (BRASIL, 2006, p.16).

O PNAE Tem como objetivo auxiliar o crescimento e o desenvolvimento biopsicossocial da educação escolar, e dessa forma se privilegia a aprendizagem, rendimento escolar e a formação de hábitos saudáveis, através de adequada base nutricional, enquanto os alunos permanecem na escola (BRASIL, FNDE, 2014). Os beneficiários do programa são alunos da educação infantil (creches e pré-escolas), do ensino fundamental, da educação indígena, os educandos remanescentes de quilombo e os alunos da educação especial, e também são inclusos os alunos de escolas filantrópicas de acordo com o Censo Escolar do ano anterior (BRASIL, PNAE).

\footnotetext{
${ }^{4}$ Criado em 2004 pelo governo federal que oferece bolsas integrais ou parciais em instituições privadas de educação superior.
} 
O governo federal financia o Programa de forma suplementar, por meio de repasses as instituições executoras (Estados, Municípios, e escolas federais) em dez parcelas mensais entre os meses de fevereiro a novembro. Esse repasse é feito pelo Fundo Nacional de Desenvolvimento da Educação (FNDE), responsável por calcular os valores financeiros repassados, criação de normas, acompanhamento, monitoramento, fiscalização e avaliação da execução do programa. A verba investida tem como fim garantir 200 dias letivos baseados no quantitativo de alunos matriculados em cada etapa de ensino.

Em relação a acesso ao PNAE, em 2017, o município de Marituba recebeu um montante de R\$ 2.333.365,20 valor abaixo do recebido em 2016 onde o total foi de $\mathrm{R} \$ 2.474 .940,00$ (gráfico 3). De maneira geral ocorreram variações positivas, de 2010 a 2013, e queda em 2014, em 2015 oscilou para mais (de $\mathrm{R} \$ 2.481 .172,00$ para $\mathrm{R} \$ 2.925 .756,00)$. A baixa nos anos de 2016 e 2017 pode ser reflexo no declínio do número de alunos matriculados já que o repasse é feito baseados nesses dados. Até maio de 2018 o repasse para o Programa no município foi de R \$1.086.592,00.

Gráfico 3: Repasse de recursos do PNAE ao município de Marituba, estado do Pará, de 2010 a 2017.

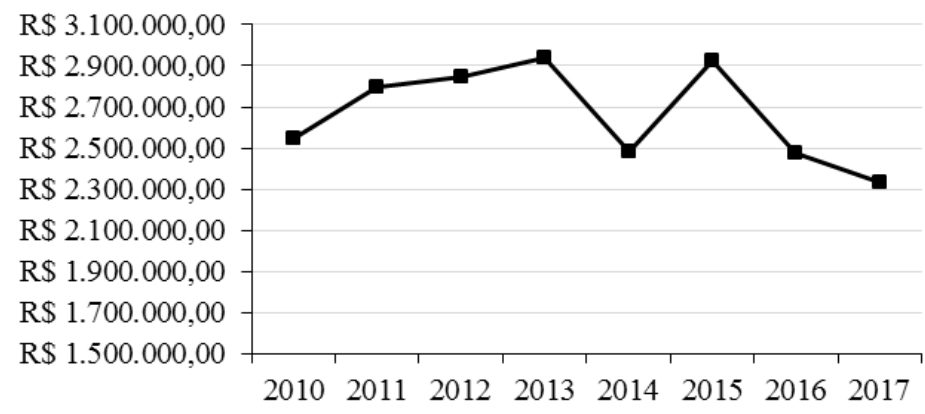

Fonte: FNDE, SIGEF - Sistema Integrado de Gestão Financeira.

O PNAE deve adquirir gêneros alimentícios direcionados a alimentação escolar e um de seus fornecedores é a agricultura familiar, onde através do artigo 14, da Lei no 11.947 de 16 de junho de 2009, no mínimo 30\% do repasse feito pelo FNDE dever ser utilizado na compra de produtos "de gêneros alimentícios diretamente da agricultura familiar e do empreendedor familiar rural ou de suas organizações, priorizando-se os assentamentos da reforma agrária, as comunidades tradicionais indígenas e comunidades quilombolas" (BRASIL, p. 4, 2009). Esse pacto é importante para o fortalecimento econômico e social da agricultura familiar regional, pois, valoriza a produção regional e as características e gostos nutricionais da população promovendo o desenvolvimento local.

Conforme dados da Secretaria de Educação Municipal de Marituba o município não contribui com o repasse do governo federal, referente ao PNAE, a verba é exclusivamente federal. Outro dado levantado na secretaria refere-se à participação dos agricultores do município vizinho, Ananindeua, como fornecedor dos produtos agrícolas, já que Marituba normalmente não produz volume regular e constante de produção para atender a demanda do programa, e ainda se pode acrescentar dificuldades dos produtores em possuir

a Declaração de Aptidão ao Programa Nacional de Fortalecimento da Agricultura Familiar (DAP/PRONAF), o que os impede de emitir nota fiscal como produtores ou associação/cooperativas. (BRASIL, TRIBUNAL DE CONTAS DA UNIÃO, 2017). Conforme a Cartilha para conselheiros do Programa Nacional de Alimentação Escolar (2017) elaborada através do Tribunal de Contas da União, esses obstáculos podem contribuir para a flexibilização do montante dos $30 \%$ de compra da agricultura familiar e esse pode ser um dos motivos que levaram a diminuição do acesso à verba do PNAE no município, como mostrado no gráfico anteriormente. 
Além das dificuldades na participação dos produtores regionais nos processos de licitação do PNAE, o quadro de funcionários da Secretaria de Educação é pequeno, somente duas nutricionistas e uma estagiária que acompanham e elaboram o cardápio das 76 escolas, 2 anexos e 5 unidades de Atendimento Educacional Especializado (AEE).

Agricultura

O censo agropecuário de 2006 mostrava que Marituba possuía 142 unidades de estabelecimentos agropecuários, sendo 116 considerados estabelecimentos de Agricultura Familiar e 26 não familiar, totalizando uma área aproximada de 5.498 hectares o que a colocava em $138^{\circ}$ posição no ranking relacionado ao tamanho de área, entre os municípios do Estado do Pará. Daqueles estabelecimentos, 2.677 hectares possuíam construções ou benfeitorias, onde 2.240 produziam lavouras permanentes e 56 lavouras temporárias, além de três hectares utilizados para o cultivo de flores, viveiros de mudas, estufas de plantas e casas de vegetação. Os resultados preliminares do censo agropecuário de 2017, mostraram aumento da área dos estabelecimentos agropecuários (72.488 hectares). Por outro lado, o número de estabelecimentos caiu para 51 unidades. Esses dados podem indicar um crescimento extensivo na agricultura municipal, ou seja, há um aumento na área de produção. Em contrapartida, não se observa um crescimento intensivo, onde ocorre aumento na produtividade e, portanto, não mostra sua eficiência.

Um mecanismo importante para agricultura familiar municipal é a DAP, pois, é o documento de identificação da agricultura familiar, necessária a participação em programas como o PNAE, por exemplo. Além disso, a DAP pode ser utilizada para indicar o grau de organização (pessoas jurídicas) dos produtores, seja em associações ou cooperativas e sua participação em operações de crédito rural, como o Programa Nacional de Fortalecimento da Agricultura Familiar (Pronaf) e outros incentivos do governo. Em Marituba, das 187 DAPs é possível constatar o pequeno número de DAPs ativas (41) em relação às inativas (146), no ano de 2017, o que nos sugere baixo acesso aos programas do governo, podendo refletir no desenvolvimento dos agricultores regionais.

Conforme trabalho realizado por Silva (2012), nos dois maiores bairros de Marituba, a saber Uriboca e Almir Gabriel, 55\% dos agricultores obtinham sua renda exclusivamente da agricultura, ainda que algumas famílias buscassem complementar suas rendas com atividades diversas, $25 \%$ dos entrevistados desenvolviam atividades agrícolas há 10 anos, enquanto 55\% relataram sempre estar envolvidos com a agricultura. A produção advinda dos bairros era prioritariamente para venda e o restante para o autoconsumo da família. O tamanho das propriedades era inferior a um hectare $\left(10.000 \mathrm{~m}^{2}\right)$ o que demonstra outra característica importante da produção de hortaliças em Marituba, sua aplicabilidade em pequenas áreas. Outro dado importante é o autorreconhecimento do produtor como agricultor familiar, bem como produtores familiares.

A produção nos locais supracitados era essencialmente de hortaliças folhosas e contava com características produtivas diversificadas, como convencional, hidropônica e mesmo a orgânica, retratando sua diversidade produtiva. Aliada à produção de hortaliças, foi observado o cultivo de plantas ornamentais, medicinais e frutíferas (SILVA, 2012).

Apesar de a produção principal estar focada nas hortaliças, Marituba apresenta um efetivo de 100.000 cabeças de galináceos. O segundo maior efetivo é o de suíno, total que chega a 350 mil cabeças, seguido por bovinos, 266 mil cabeças (IBGE- PESQUISA PECUÁRIA MUNICIPAL, 2016). Mesmo com esse número de galináceos, a produção de ovos em Marituba é muito baixa (200 mil dúzias). A mesma situação se aplica a Belém. Isso pode caracterizar um efetivo de galináceo essencialmente para abate (tabela 9). 
Tabela 9: Produção de origem animal (leite e ovos de galinha) nos municípios de Marituba, Belém e no Estado do Pará.

\begin{tabular}{ccc}
\hline Tipo de produto de origem animal & Marituba & Belém \\
\hline Leite (Mil litros) & 28 & 33 \\
Ovos de galinha (Mil dúzias) & 200 & 31 \\
\hline
\end{tabular}

Fonte: IBGE- Pesquisa Pecuária Municipal, 2016.

A produção agrícola em Marituba ainda é pouco desenvolvida, apesar de, no passado, ter demonstrado uma relativa contribuição, em vista dos trabalhos já citados. Atualmente, o município precisa reestruturar sua capacidade produtiva agrícola, tendo a perspectiva da AUP. Nesse contexto, há necessidade de aproximar em tarefa conjunta, as agências de assistência técnica, o poder público municipal e os agricultores, todos em busca de aprimorar as características positivas e melhorar as negativas, do município.

\section{Saúde}

A longevidade é representada pela "esperança de vida ao nascer" e avalia "o número médio de anos que as pessoas viveriam a partir do momento do nascimento, mantendo os padrões de mortalidade observados em cada período" (PNUD, 2013, p. 91). Esse dado indica aumento entre os anos de 2000 e 2010 de 65,7 para 72,6 anos o que pode indicar progresso nas condições de vida e saúde da população (tabela 10).

Tabela 10: Longevidade e fecundidade no município de Marituba no período de 2000 a 2010.

\begin{tabular}{ccc}
\hline Longevidade, Fecundidade - Marituba - PA & $\mathbf{2 0 0 0}$ & $\mathbf{2 0 1 0}$ \\
\hline Esperança de vida ao nascer (\%) & 65,7 & 72,6 \\
Taxa de fecundidade total (\%) & 3,2 & 1,8 \\
\hline
\end{tabular}

Fonte: IBGE/Censos Demográficos 2000 e 2010.

A taxa de fecundidade total é medida por número médio de filhos nascidos vivos, tidos por uma mulher ao final de seu período reprodutivo, na população residente em determinado espaço geográfico, no ano considerado. A taxa é estimada para um ano determinado, a partir de informações retrospectivas obtidas em censos e inquéritos demográficos. Na região de estudo essa taxa foi de $1,8 \%$ e conforme o Instituto de Pesquisa e Estratégia Econômica do Ceará (IPECE) taxas inferiores a 2,1 são indicadoras de fecundidade insuficiente pelo menos para assegurar a reposição populacional (IPECE, 2010, p. 26).

Em Marituba existem 38 estabelecimentos de saúde, distribuídos entre estaduais, municipais e privados (BRASIL, Ministério da saúde, CNESNet, 2018). Outro parâmetro importante a respeito da saúde no município é o número de leito hospitalar por mil habitantes que, em 2015, era de 1,38, em 2016 sofreu leve aumento para 1,44. O número de médicos por 10 mil habitantes também foi ampliado de 4,23 (2015) para 4,46 (2016), essa conjuntura pode_ter colaborado com a baixa taxa de mortalidade infantil conforme parâmetros da Organização Mundial de Saúde (OMS) que é de 10\% ao ano e que será discutido a seguir.

A mortalidade infantil é calculada segundo o número de óbitos de menores de um ano de idade, por mil nascidos vivos em determinada população, espaço geográfico e época (IPECE, 2010). No gráfico 4 é mostrado a taxa bruta de mortalidade infantil compreendida entre os anos de 2011 a 2015, e em 
Marituba houve queda nos números relacionados a mortalidade de 4,98\% (2011) para 4,52\% (2015). Na contramão, os municípios de Belém e Ananindeua (Região Metropolitana de Belém) apresentaram aumento de 0,61 e $0,37 \%$, respectivamente, no mesmo período. Assim como a taxa estadual também sofreu acréscimo de $0,31 \%$. A queda da mortalidade infantil, no município de estudo pode indicar atenção mais adequada a saúde por meio do avanço no número de estabelecimentos de saúde, como mostrado anteriormente, além do aumento a atenção ao parto e aos cuidados com os recém-nascidos (MALTA et al., 2010). Ainda se pode incluir ações voltadas a educação em saúde com destaque às mulheres em idade reprodutiva e melhoria no saneamento básico.

Gráfico 4: Taxa bruta de mortalidade infantil entre os anos de 2011 e 2015.

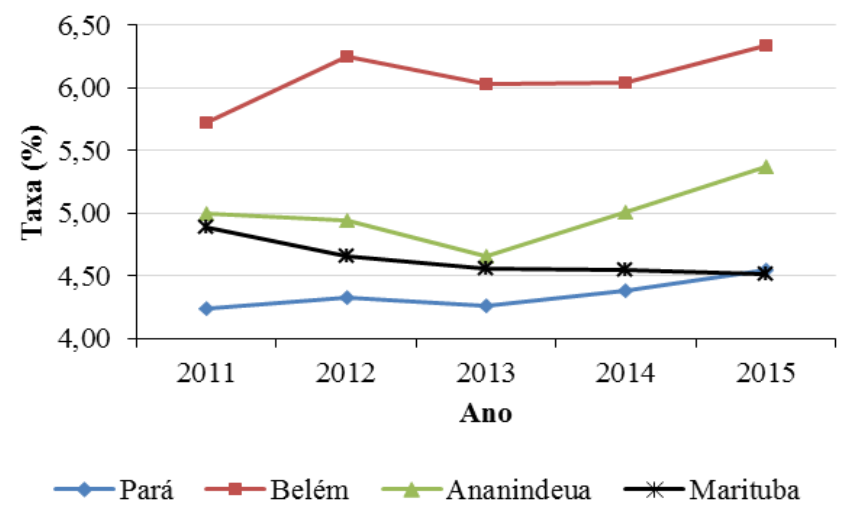

Fonte: FAPESPA, 2011/2015.

\section{Saneamento Básico}

De maneira geral, o saneamento básico se projeta de forma tímida, se comparada a capital, Belém. Segundo o Sistema de Indicadores Sociais (SIIS, 2010), o percentual de domicílios com abastecimento de água na rede geral, na capital chegou a 73,76\%, enquanto em Marituba demonstrou somente 17,78\%, sendo a zona urbana 3.017 e a rural 11 domicílios de um total de 3.027. A outra parte da população utilizava diferentes alternativas de abastecimento como poços ou nascentes, e na área urbana o uso foi de 9.944 e na rural 1.405 o que totalizou $66,66 \%$ do total de domicílios. Os $15 \%$ restantes faziam uso de outras formas de abastecimento, como coleta direta nas nascentes de água.

O total de domicílios ligados a rede geral de esgoto ou pluvial, na zona urbana, indicou 61 domicílios, enquanto na zona rural não houve registro. De modo geral, a taxa de residências ligadas à rede de esgoto sanitário representou somente 0,36\%, enquanto em Belém essa taxa foi de 25,99\%. Os métodos de disposição final de efluentes domésticos mais utilizados na região eram: Fossa Séptica, Fossa Rudimentar, Vala, Rio, Lago ou Mar e Outro Escoadouro. Sendo a Fossa Séptica a mais utilizada por $58,28 \%$ dos domicílios, onde 9.044 na cidade e 879 na zona rural. O segundo método mais utilizado foi a Fossa Rudimentar empregado por 3.850 habitações urbanas e 895 rurais. Esses dados refletem situação semelhante à do Brasil, pois, segundo a Fundação Nacional de Saúde (FUNASA), em 2012, 64\% dos domicílios urbanos tinham acesso à rede de esgoto sanitário, enquanto os rurais, aproximadamente $75 \%$ se valiam de sistemas inadequados devido às dificuldades de uso das tecnologias de coleta, transporte e tratamento de efluentes domésticos empregados na área urbana.

A coleta de lixo domiciliar alcançava 50,51\% da população, enquanto em Belém, 95,39\% (SIIS, 2010). Logo, observou-se que na capital existe uma representação mais favorável em termos de coleta de resíduos sólidos o que pode ser reflexo de políticas públicas de limpeza inseridas no município. Em Marituba ainda há necessidade de melhoria nos aspectos de saneamento básico dentre outros, coleta de 
lixo, a fim de colaborar para uma das principais dimensões do IDHM, a saúde.

\section{CONSIDERAÇÕES FINAIS}

O diagnóstico mostrou o precário desenvolvimento do município de Marituba em relação a Belém, com respeito a infraestrutura, principalmente, de segurança e saneamento básico, mesmo Marituba estando situada às proximidades do centro urbano. Por outro lado, referente à educação e saúde, o município apresenta características de relativo desenvolvimento, já que possui um IDHM considerado médio em relação aos outros municípios brasileiros. Neste caso, as dimensões educação e saúde tiveram forte influência na melhoria do IDHM, o que pode ter sofrido influência do constante acesso da população aos programas do governo, como o Bolsa Família e o PNAE que buscam contribuir para o desenvolvimento dos beneficiários; influência esta que foi identificada em outros trabalhos de pesquisa.

A agricultura em Marituba funciona em sistema diversificado, e é essencialmente produtora de hortaliças, que são complementadas com plantas medicinais, ornamentais e frutíferas. Há produção de pequenos animais, ovos e leite, porém em pequena quantidade. De maneira geral, a agricultura é desenvolvida em áreas reduzidas para fins de comércio e autoconsumo e pode ser caracterizada como familiar e urbana e periurbana, pois é conduzida em áreas próximas ao centro urbano e possui mão de obra de cunho familiar.

As características socioeconômicas de Marituba retratam um município em desenvolvimento pois se observou, através dos dados discutidos, uma tendência de melhoria em alguns setores como IDHM, principalmente nas vertentes educação e saúde, e redução da desigualdade através do índice de Gini. Nessa conjuntura a AUP pode ser mais uma contribuição no processo de ampliação das melhorias no município já que se utiliza de incentivos ao conhecimento local afim de promover a igualdade e participação dos produtores, também estimula a gestão urbana, social e ambiental conforme trabalho realizado por Da Silva Lemos (2014). As políticas públicas são fortes promotoras para agricultura urbana e periurbana e através do diagnóstico, conhecendo a realidade regional é possível construir fundamentações para que estas sejam criadas a fim de promover o desenvolvimento regional.

Estas políticas públicas podem ser desenhadas de forma a considerar o potencial de Marituba, sob a ótica da AUP. Algumas características observadas no diagnóstico podem ajudar nessa visão mais holística, onde a localização, por exemplo, próximo aos centros consumidores, pode reduzir gastos com escoamento de produção, e acesso fácil dos consumidores aos produtos e assim conhecer a origem dos produtos que consome. A experiência adquirida ao longo do tempo é outra característica importante dos produtores maritubenses, que assim, se permitem absorver novas formas produtivas, inclusive mais sustentáveis, empreender e ampliar sua produtividade.

Para desenvolver a AUP faz-se necessário articular as instituições de assistência técnica e órgãos do poder público. As ações podem incentivar a participação dos agricultores no PNAE, programa do governo de compra e distribuição de alimentos para a merenda escolar, onde os produtores teriam oportunidade de favorecer as crianças de sua própria comunidade, com alimentos saudáveis e regionais; desenvolver o empreendedorismo em sua produção, além de garantir um comprador para seus produtos.

O diagnóstico é importante na construção do panorama local, porém, somente o diagnóstico em si não pode ser tomado como única fonte para retratar o contexto social do município, isso é devido ao fato de que alguns pontos do diagnóstico socioeconômico não puderam ser tão bem tratados em decorrência de restrições, como insuficiência de dados atualizados. Podendo levar a não equivalência entre a realidade indicada pelos bancos de dados e a vivenciada pela população, além de mostrar uma deficiência 
deficiência na coleta de informações para embasar pesquisas importantes à sociedade.

Então, sugere-se para este problema de coleta de dados que haja criação de um banco e dados, onde pesquisadores, entidades e órgãos governamentais oficiais, conjuntamente, possam atualizar constantemente as informações importantes a esse tipo de diagnóstico, não necessariamente aguardando as coletas oficiais que muitas vezes demoram e necessitam de altos investimentos. Então, há necessidade de trabalhos futuros que busquem qualidade e que gerem informações socioeconômicas a fim de servir como base para o banco de dados sugerido.

\section{REFERÊNCIAS}

ATLAS DO DESENVOLVIMENTO HUMANO. PNUD. 2010. Disponível em: http://www.atlasbrasil.org.br/2013/pt/perfil_m/3207. Acesso em: 25 fev. 2018.

BRASIL, Ministério da Saúde. Departamento de informática do Sistema Único de Saúde do Brasil (DATASUS) 2008 - 2015. Disponível em: < http://www2.datasus.gov.br/DATASUS/index.php?area=0205>. Acesso em 03 fev. 2018.

BRASIL, Ministério do Desenvolvimento Social e Agrário (MDSA). Disponível em < http://mds.gov.br/area-de-imprensa/noticias/2017/marco/mdsa-lanca-ferramenta-para-aperfeicoar-agestao-dos-programas-sociais>. Acesso em 03 jun. 2018.

BRASIL, Programa Universidade para Todos (Prouni). Disponível em: < http://siteprouni.mec.gov.br/>. Acesso em: 25 jan. 2018.

BRASIL. Ministério da Educação. Inep. Disponível em: :< http://portal.inep.gov.br/ideb >. Acesso em: 25 fev. 2018.

BRASIL. Ministério da saúde, Cadastro Nacional de Estabelecimentos de Saúde (CNESNet). Disponível em: <

http://cnes2.datasus.gov.br/Mod_Status_Carga_Arquivos.asp?nom_arq=CNES1504422802201808210220 184021.BCK >. Acesso em: 20 março 2018.

BRASIL. Ministério da saúde. Departamento de informática do Sistema Único de Saúde do Brasil (DATASUS). Disponível em: < http://tabnet.datasus.gov.br/cgi/ibge/censo/cnv/ginibr.def > . Acesso em: 17 fev. 2018.

CNAU - Centro Nacional de Agricultura Urbana. Disponível em: <http://aspta.org.br/2015/04/cau/>. Acesso em: 21 fev. 2018.

BELTRAN, J, 1995. Hacia un imaginario de desarrollo sostenible. In: A la búsqueda de ciudades sostenibles. SEMINARIO ESPECIALIZADO; ENCUENTRO INTERNACIONAL

HABITAT, 2, Pereira, Colombia. Memorias... Pereira, Bogotá: Ed. Guadalupe. 369 p.

CONFERÊNCIA NACIONAL DE SEGURANÇA ALIMENTAR E NUTRICIONAL, 2, 2004, Olinda. Relatório Final. Disponível em:< http://bvsms.saude.gov.br/bvs/publicacoes/II_Conferencia_2versao.pdf $>$. Acesso em: 04 fev 2018.

CONFERÊNCIA NACIONAL DE SEGURANÇA ALIMENTAR E NUTRICIONAL, 3, 2007, Olinda. Documento Final, Fortaleza. Disponível em: $<$ http://www.ibfan.org.br/documentos/outras/doc-254.pdf $>$ Acesso em: 04 fev 2018. 
FAPESPA - Fundação Amazônia de Amparo a Estudos e Pesquisas do Pará. Estatísticas Municipais Paraenses: Marituba. / Diretoria de Estatística e de Tecnologia e Gestão da Informação. - Belém, 2015.49 f.: il. Disponível em: <http://www.fapespa.pa.gov.br/menu/151>. Acesso em: 15 jan. 2018.

FNDE - Fundo Nacional de Desenvolvimento da Educação. Disponível em: < http://www.fnde.gov.br/ $>$. Acesso em: 15 jan. 2018.

SIGEF - Sistema Integrado de Gestão Financeira. Disponível em: < https://sigef.incra.gov.br/ >. Acesso em: 20 fev. 2018.

FUNASA - Fundação Nacional de Saúde. Saneamento rural. Disponível em: <

http://www.funasa.gov.br/web/guest/panorama-do-saneamento-rural-no-brasil>. Acesso em maio de 2018.

FJP - Fundação João Pinheiro. Disponível em: < http://www.fjp.mg.gov.br/index.php/base-de-dados >. Acesso em: 21 jan. 2018.

IBGE- Censo demográfico, 1991, 2000 e 2010.

IBGE- Pesquisa Pecuária Municipal, 2016. Disponível

em<https://sidra.ibge.gov.br/tabela/3939\#resultado $>$. Acesso em: 02 fev. 2018.

INEP - Instituto Nacional de Estudos e Pesquisas Educacionais Anísio Teixeira. Disponível em: <http://ideb.inep.gov.br/resultado/resultado/resultado.seam?cid=39429 >. Acesso em: 31 jan. 2018.

Ipeadata - Instituto de Pesquisa Econômica Aplicada. Disponível em: < http://www.ipeadata.gov.br/Default.aspx >. Acesso em: 25 jan. 2018.

MARITUBA, Prefeitura Municipal. Plano Diretor Participativo de Marituba. Marituba, 2007.

Disponível em: < http://www.marituba.pa.gov.br/site/o-municipio/historia/ >. Acesso em: 01 fev. 2018.

PNUD - Programa das Nações Unidas para o Desenvolvimento. Disponível em:

<http://www.atlasbrasil.org.br/2013/pt/perfil_m/3207>. Acesso em: 25 fev. 2018.

RELATÓRIO final da CAAUP/ RMB - Centro de apoio à Agricultura Urbana e Periurbana da Região Metropolitana de Belém. 2010. Disponível em: < https://issuu.com/caaupbelem/docs/relat_rio_20final_20caaup_1_1_>. Acesso em: 15 jan de 2018.

RAMÃO, F. P. et al. Espaço urbano e criminalidade violenta: análise da distribuição espacial dos homicídios no município de Cascavel/PR. 2008. Disponível em: <

http://www.scielo.br/pdf/rsocp/v18n35/v18n35a13.pdf> Acesso em: 25 fev. 2018.

BRASIL, Portaria n 467 de fevereiro de 2018. Institui o Programa Nacional de Agricultura Urbana e Periurbana. Diário Oficial da União, Brasília, fev. 2018.

BRASIL. Ministério da Educação. Cartilha Nacional de Alimentação Escolar. Brasília, 2014. 87 p.

Brasil. Tribunal de Contas da União. Cartilha para conselheiros do Programa Nacional de

Alimentação Escolar (PNAE) / Tribunal de Contas da União, Fundo Nacional de Desenvolvimento da Educação, Conselho de Alimentação Escolar; Apresentação Raimundo Carreiro, Sílvio de Sousa Pinheiro. 6. ed. Brasília : TCU, 2017. 119 p. il.

CAMPOS, A. C. V.;Gonçalves, L. H. T. (2018). Perfil demográfico do envelhecimento nos municípios do estado do Pará, Brasil. Rev Bras Enferm, 71(Suppl. 1), 636-643.

DA SILVA LEMOS, N; DE ANDRADE, L. M. S; DE MEDEIROS, V. A. S. Desafios do Planejamento Urbano no Brasil e seus Marcos Legais sob a Ótica da Agricultura Urbana. Paranoá: cadernos de arquitetura e urbanismo, n. 14, 2015. 
DA NÓBREGA JÚNIOR, J.M.P. Diagnóstico socioeconômico do Cariri Ocidental paraibano: avanços sociais e desigualdade interna. Revista Espaço Acadêmico, v. 15, n. 174, p. 90-97, 2015.

DAL MORO, P., et al. Diagnóstico ambiental de indústrias de fabricação de estruturas metálicas e esquadrias de metal de pequeno e médio porte. Gestão \& Produção, v. 22, n. 1, p. 229-237, 2015.

FAO -Organização das Nações Unidas para agricultura e alimentação. MDS - Ministério de Desenvolvimento Social. Sistematizar e analisar a implementação da Política Nacional de Agricultura Urbana e Periurbana promovida pelo Ministério de Desenvolvimento Social e Combate à Fome no Brasil com foco em regiões Metropolitanas durante o período 2004-2009. Consolidado, 2011.

IPECE - Instituto de Pesquisa e Estratégia Econômica do Ceará. Entendendo os principais indicadores sociais e econômicos. Fortaleza, 2010. 131 p.

JANNUZZI, P.M. Indicadores para diagnóstico, monitoramento e avaliação de programas sociais no Brasil. Revista do Serviço Público, Brasília, v.56, n.2, p137-160, Abr/Jun 2005).

KUHN, D. D, TONETTO, E. S. O Programa Bolsa Família e os Indicadores Sociais de Combate à Pobreza no Rio Grande do Sul: Um Olhar Multidimensional. Desenvolvimento em Questão, [S.1.], v. 15, n. 39, p. 86-111, maio 2017.

LIMA, J. J, CARDOSO, A. C. HOLANDA, A. C. Impasses e desafios na gestão da Região Metropolitana de Belém. Cadernos Metrópole Desigualdade e Governança, nº 14, 2ºmestre 2005.

LIMA, L, ANDRADE, M, BARCELOS, V. Diagnóstico socioeconômico como instrumento de gestão regionalizada e participativa. 2013.

MALTA, D. C., et al. Mortes evitáveis em menores de um ano, Brasil, 1997 a 2006: contribuições para a avaliação de desempenho do Sistema Único de Saúde. Cad. Saúde Pública [online]. 2010, vol.26, n.3, pp.481-491. ISSN 0102-311X.

MALTA, D. C., et al. Inquéritos Nacionais de Saúde: experiência acumulada e proposta para o inquérito de saúde brasileiro. Revista Brasileira de Epidemiologia, v. 11, p. 159-167, 2008.

MEREGE, R. C. C. B. Levantamento socioeconômico com foco no saneamento do Bairro Ilhota em Itapema, Santa Catarina. Florianópolis: UFSC, 2011. 142 f.

MOUGEOT, L. J. A. Agricultura urbana - conceitos e definições. Revista de Agricultura Urbana, RUAF - Centro de Recursos em Agricultura e Silvicultura Urbanas, jul. 2000. Disponível em: < http://www.agriculturaurbana.org.br/RAU/AU01/AU1 conceito.html >. Acessado em: 31 de jan. 2018.

NEVES, L. C. A. et al. Contribuição do centro de agricultura urbana e periurbana da região metropolitana de Belém para a segurança alimentar em assentamento periurbano. Braz. J. Food Technol., III SSA, novembro 2010.

NÉRI, M. VAZ, F. M. SOUZA, P. H. G. F. Efeitos macroeconômicos do Programa Bolsa Família: Uma análise comparativa das transferências sociais. Efeitos Macroeconômicos do Programa Bolsa Família. Instituto de Pesquisa Econômica Aplicada (IPEA). Pp. 193-206. 2013.

SANTANA. A. C.; SEQUEIRA, G. R; OLIVEIRA, C. M; et al. Mercado Institucional e Agricultura Urbana E Periurbana em Curuçambá, Ananindeua, Pará: Oportunidades e desafios. Revista Brasileira de Gestão e Desenvolvimento Regional. 2016. 
SANTOS, M. A. S.; SILVA, M. Y.C. Agricultura urbana e periurbana na Região Metropolitana de Belém: Um estudo de caso exploratório com produtores de hortaliças no município de Marituba. Movendo Ideias, Belém, v 12. n.1, p. 85-96, 2007. Disponível em: <

https://www.researchgate.net/publication/319288957_Agricultura_urbana_e_periurbana_na_Regiao_Metr opolitana_de_Belem_um_estudo_exploratorio_com_produtores_de_hortalicas_no_municipio_de_Maritub a >. Acesso em: 20 março 2018.

SIIS - Sistema de Informações de Indicadores Sociais do Estado do Pará, 2010. Disponível em: <https://www2.mppa.mp.br/sistemas/gcsubsites/upload/53/marituba(2).pdf>. Acesso em: 20 mar. 2018.

SILVA, J. S, 2018. Ilustração da Região Metropolitana de Belém. Base Vetorial IBGE. SRC: SIRGAS 2000. Disponível em: < https://issues.pangaea.de/browse/PDI-18831>.

SILVA, P. O, 2012. A reprodução da agricultura familiar na Região Metropolitana de Belém no início do século XXI: um estudo acerca dos agricultores dos bairros de Almir Gabriel e Uriboca no município de Marituba - Pará / Dissertação (Mestrado) - Universidade Federal do Pará, Instituto de Filosofia e Ciências Humanas, Programa de Pós-Graduação em Geografia, Belém, 2012.

SOUZA, M. J. L. 2004. Alguns aspectos da dinâmica recente da urbanização brasileira. In: FERNANDES, E. \& VALENÇA, M. (orgs.).Brasil urbano. Rio de Janeiro: Mauad. UNDP - UNITED NATIONS DEVELOP PROGRAM. Human Development Report 1996. New York; Oxford: OUP, 1996.

TACHIZAWA, T. 2009. Sustentabilidade e responsabilidade social: proposta de modelo de diagnóstico socioambiental baseada em pesquisa empírica. Revista Produção Online, v. 9, n. 4, p. 795-821.

TÔSTO, S. G., BRANDÃO, E. S., SAID, U. P., ANJOS, G. T. 2003. Diagnóstico socioeconômico dos municípios da região noroeste do Estado do Rio de Janeiro. Embrapa Solos-Boletim de Pesquisa e Desenvolvimento (INFOTECA-E), n. 41 p. 103. 